\title{
PGPR Improves Yield of Strawberry Species under Less-Fertilized Conditions
}

\author{
Takeshi Kurokura, Sumika Hiraide, Yoshitake Shimamura and Kenji Yamane \\ Faculty of Agriculture, Utsunomiya University, Tochigi 321-8505, Japan
}

(Received January 4, 2017; Accepted March 7, 2017)

\begin{abstract}
Plant growth promoting rhizobacteria (PGPR) is applied as biofertilizer to expect better production potential on commercial crops while keeping sustainability, but their function is dependent on the combination of PGPR and target crops. It has been reported that the application of PGPR in the soil resulted in the increment of strawberry yield, but other reports argue that PGPR has no effect on the yield potential. In addition, it is not clear whether the application timing of PGPR affects in a forcing cultivation system which usually requires transplanting. In this study, responses of diploid wild strawberry (Fragaria vesca) and garden strawberry (F.× ananassa Duch.) varieties to PGPR application were examined. Application of PGPR, Bacillus cereus KI-2, during the flower induction increased the total yield and number of fruits in $F$. vesca 'Hawaii-4', and in garden strawberry 'Hoko-wase'. The application resulted in earlier flowering in 'Hoko-wase' while no difference was observed in 'Tochi-otome'. Sucrose content was also altered in cultivar dependent manner so that it was increased in 'Hawaii-4', while it was decreased in 'Tochi-otome'. These results indicate that PGPR has a potential to improve the yield factors while keeping the quality of the fruits, but the effect is cultivar dependent.
\end{abstract}

Keywords : Bacillus cereus, biofertilizer, flower induction, Fragaria, sugar content

\section{INTRODUCTION}

Modern agriculture techniques are conscious of sustainability, while meeting consumers' demand on yields and quality (Tilman et al., 2002). To achieve sustainability, several tools have been applied. One of them, plantmicroorganisms interaction has been found as a potential method to improve crop yield (Bhattacharyya and Jha, 2012). Plant roots in the soil contacts not only minerals and water but also microorganisms present in the soil, and the interaction between plants and these microorganisms affects plant growth. For example, arbuscular mycorrhizal (AM) fungi establish symbiosis with plants and they are thought to help plants' phosphor uptake (Bhattacharyya and Jha, 2012). The benefit of the inoculation of AM into soil is not limited to improvement of nutrition uptake, their ability to maintain soil structure and moderate water stress, alleviation of toxicity of some metal ions, as well as help defense against pathogen have been reported (Cardoso and Kuyper, 2006). As AM and other biofertilizers are isolated from natural conditions, the application of such bioagents is thought to contribute sustainability of the growth environment while keeping productivity (Cordier et al., 2000).

Plant Growth Promoting Rhizobacteria (PGPR) is defined as rhizosphere bacteria whose interaction with plants helps plant growth. PGPR helps various aspects of plant life cycles through the interaction to plants. This includes growth promotion of plants by supporting nutrition uptake, antagonizing or adding resistance to pathogens, production of plant hormones, and modification of physical structure of the soil (Bhattacharyya and Jha, 2012). Applications of PGPR in growth media or direct application to plant body during cropping are carried out to expect better yield as a result of plant/PGPR interaction. Positive effects of PGPR on commercial products have been reported in many crops such as soybean (Cattelan et al., 1999), maize (Babalola et al., 2003), tomato (Silva et al., 2004) as well as rice (Sen and Chandrasekhar, 2014).

Strawberry (Fragaria $\times$ ananassa Duch.) is an important cash crop grown mainly in temperate climate zone. Its production in the world reaches to over 7.7 million tons per year and is still growing (FAO, 2013). Strawberry fruits are rich in health improving agents including antioxidant agent such as anthocyanins, other phenolic compounds and vitamins, as well as sugars. The content of such compounds vary according to environmental conditions including the soil fertility (Tulipani et al., 2008). Thus the application of PGPR could be a method to improve the content of these beneficial compounds while keeping sustainability of the cultivation field. Strawberry (Fragaria spp.) is a perennial herbaceous rosette which belongs to genus Fragaria. Garden strawberry (F.× ananassa Duch.) is a commercial octoploid species which is thought to originate in part from diploid wild strawberry, $F$. vesca (Hirakawa et al., 2014). Strawberries have two modes of reproduction; vegetative through stolons (runners) and sexual through flowers and fruits. Strawberry has the sympodial growth habit so that new flower truss (inflorescence) emerges from the axil of the older inflorescence (Kurokura et al., 2005). The inflorescence is the cyme, the initial (first) flower is followed by two secondary flowers

Corresponding author: Takeshi Kurokura, fax: + 81-28-649-5401, e-mail : kurokura@cc.utsunomiya-u.ac.jp 


\section{T. KUROKURA ET AL.}

and this structure unit repeats several times. The balance between the vegetative propagation and the flowering depends on the environmental conditions such as photoperiod, temperature (Battey et al., 1998). Fragaria cultivars are divided into two groups in terms of flowering habit; shortday (SD) cultivars in which runners are dominate under long-day (LD) conditions while flowering takes place under SD and cool temperature conditions, and everbearing cultivars whose flowering dominate under LD conditions and less runners are produced (Battey et al., 1998; Sønsteby and Heide, 2007). Strawberry production in Japan utilizes forcing systems in which runner plants of SD cultivars are potted in relatively small pots and subjected to low temperature and SD treatments during summer, before planted in the greenhouse (Ueki et al., 1993).

Application of PGPR in strawberry production has been reported in some studies for its effects on increment of number of runners as well as fruits yield (for example, Esitken et al., 2010; Erturk et al., 2012; Lowe et al., 2012). It has been also reported the application improved anthocyanin content (Lingua et al., 2013). Other report has claimed that the application of PGPR in strawberry production can soften salt stress and improve the yields and fruit nutrition factors (Karlidag et al., 2013). Recent study has argued that the inoculation timing of AM fungi on the plant has significant effects on the responses of the plants (Palencia et al., 2015). These indicate the possibility of PGPR as a method to reduce the use of chemical fertilizer and maintain sustainability. However, less is known how PGPR affects the productivity of strawberry in forcing culture typical in Japanese cultivation system and cultivars despite the practical use of PGPR by some growers. Therefore, in this study, one of the commercially available Bacillus PGPR, Bacillus cereus KI-2 was used to clarify the effects of PGPR, not only on the yield factors but also on the sugar composition, which directly reflected in the quality/taste of the fruits. Our results provide the varietal difference and the effect of application timing on the responses to the PGPR, in terms of yield, as well as sugar compositions.

\section{MATERIALS AND METHODS}

Plant materials, growth media and growth conditions

Runner plants (ramet) of diploid LD flowering wild strawberry F. vesca 'Hawaii-4' was used for the growth cabinet experiment. Runner plants of octoploid garden strawberry F.× ananassa Duch. 'Tochi-otome' and 'Hokowase' were used in the glass house experiment. In both experiments, runner plants were cut from mother plants maintained in a growth chamber under non-flowering, runner inducible conditions, and plantlets with 2 to 3 unfolded leaves were cut and planted onto the growth media in cell trays $(5 \times 5 \mathrm{~cm})$.

The plantlets were kept humid in a growth chamber until rooting under illumination of white fluorescent tubes $\left(200 \mu \mathrm{mol} \mathrm{m} \mathrm{m}^{-2} \mathrm{~s}^{-1}\right.$ PPFD) with 12-h light/12-h dark photoperiod at $23 / 19^{\circ} \mathrm{C}$ for diploid or with $16-\mathrm{h} / 8$-h at $25 /$ $22^{\circ} \mathrm{C}$ for octoploid. After the rooting was confirmed, flowers were induced by changing the photoperiod and temperature to $18-\mathrm{h} / 6-\mathrm{h}$ at $23 / 19^{\circ} \mathrm{C}$ (LD treatment) for diploid, or $8-\mathrm{h} / 16-\mathrm{h}$ at $15^{\circ} \mathrm{C}$ constant (low-temperature/SD treatment) for octoploid. Diploid plants were block designed so that one block consists of three plants and a total of six blocks $(n=6)$ per condition were sampled.

Flower induction treatment of garden strawberry was conducted according to Kurokura et al. (2005), and the induction was confirmed under stereo microscope. After the flower induction, plants were repotted into 11 pots containing growth media and grown in a greenhouse set at 22/17 ${ }^{\circ} \mathrm{C}$ with natural day-light conditions.

Matrix of the growth media was normal peat moss $(\mathrm{pH}$ 5.0-6.0, N $180 \mathrm{mg} \mathrm{L}^{-1}$, P $120 \mathrm{mg} \mathrm{L}^{-1}$, K $220 \mathrm{mg} \mathrm{L}^{-1}$; Sakata Seed, Japan). PGPR was supplied as form of compost (biofertilizer) which contains PGPR, Bacillus cereus KI-2 (5× $10^{7} \mathrm{cfu} \mathrm{g}^{-1}$ F.W.; Bitech, Japan) at a weight of $2 \%$ to the peat moss (final concentration of $B$. cereus $\mathrm{KI}-2=1.0 \times 10^{6} \mathrm{cfu} \mathrm{g}^{-1}$ F.W.) ('With PGPR' media). The same compost was autoclaved $\left(121^{\circ} \mathrm{C}, 1 \mathrm{~atm}, 40 \mathrm{~min}\right)$ and mixed at the same ratio as 'With PGPR' media. This growth media was used as negative control ('Without PGPR' media). No fertilizer was used during the experimental period.

Sampling procedure

Number of fruits was counted on the fully ripe fruits. Fruit with shiny skin were classified as fully ripe fruit, and the judgement and sampling was conducted twice a week by naked eyes. Fresh fruit were vertically cut into two immediately after the harvest and both cuts were weighed, then the dry mass of the one half of the cut was weighed after it was processed by a freeze drier (FDU-1200, EYELA, Japan). Dry mass percentage was evaluated on the half of the cut as (dry weight) $\cdot(\text { fresh weight })^{-1} \times 100$. $^{-}$ Total fruit yield of the first flower truss was calculated after all fruits of the truss was harvested.

Weight, length, SPAD, leaf area and runner count of

$F$. vesca

Vegetative growth parameters were evaluated on $F$. vesca. Petiole length of the newest unfolded leaves was measured by a digital caliper on 20 and $35 \mathrm{~d}$ after the LD treatment. SPAD values of the newest unfolded leaves were recorded by SPAD meter (SPAD-502, Konica Minolta, Japan) on 20 and $34 \mathrm{~d}$ after the long-day treatment. Leaf area was estimated by the photograph of the newest unfolded leaves of the plants taken on $34 \mathrm{~d}$ after the long-day treatment using LIA32 (ver. 0.378; http://www.agr.nagoya-u.ac.jp/ shinkan/LIA32/) Number of runners emerged during the experiment period was counted periodically every week after the long-day treatment.

\section{Brix and sugar content analysis}

The fruits were cut vertically and one half of the cut was squashed after weighing, to evaluate Brix, while the other half was frozen at $-20^{\circ} \mathrm{C}$ after weighing. Brix of the sap of the squashed fruits was quantified for the initial and secondary fruits of the plants by digital refractometer (PAL-J, Atago, Japan).

Sugar contents were analyzed by HPLC (SCL-6B, 
Shimadzu, Japan). The frozen fruits were freeze-dried, and sugar was extracted from $50 \mathrm{mg}$ of the freeze-dried ground samples by adding $3 \mathrm{~mL}$ of $80 \%$ ethanol and $500 \mu \mathrm{L}$ of $1 \%$ rhamnose (as internal control) and heat at $80^{\circ} \mathrm{C}$ for $30 \mathrm{~min}$. Supernatant of the extracts was dried by centrifugal evaporator and suspended in $200 \mu \mathrm{L}$ of distilled water and $10 \mu \mathrm{L}$ of the suspension was used for analysis. Water: acetonitrile $(1: 3, \mathrm{v} / \mathrm{v})$ was used as move phase at a flow rate of $1.0 \mathrm{ml} /$ min, in combination with a separation column (TSK-GEL AMIDE-80; Tosoh Corp., Japan) at $80^{\circ} \mathrm{C}$ and a refractive index detector (RI-8022, Tosoh Corp., Japan).

\section{Statistical analysis}

One-way or two-way analysis of variance (ANOVA) was performed using $\mathrm{R}$ package (ver. 3.1.2) with maximum significance level set at 0.05 . When appropriate, Tukey-Kramer test was performed using multcomp package (ver. 1.4-6) as a post-hoc analysis for multiple comparison.

\section{RESULTS}

Wild strawberry ( $F$. vesca)

Runner plants of ever-bearing F. vesca 'Hawaii-4' were planted on the growth media containing live PGPR (PGPR media). To investigate if the application of PGPR affects vegetative growth of the plant, runner formation, plastchron, petiole length leaf area and SPAD were evaluated on the newest unfolded leaves, to avoid the difference in the plastchron affects the maturity of the leaflets of each plants, but no statistical difference was observed for runner formation, plastochron, petiole length, nor SPAD compared to the PGPR-inactivated control $(P>0.05)$ (Fig. 1, Table 1). However, increment in the leaf area of the newest unfolded leaves was observed by application of PGPR (Table $1)$.

The total fruits yield of the first fruit truss was higher in the PGPR media, in terms of fresh weight, as well as number of fruits (Table 2). This trend was observed at any sampling date during the experiment (data not shown). In addition, fresh weight of the initial fruit of the truss was increased by the application of PGPR (Table 2). On the other hand, despite of the increments in the leaf area, dry mass

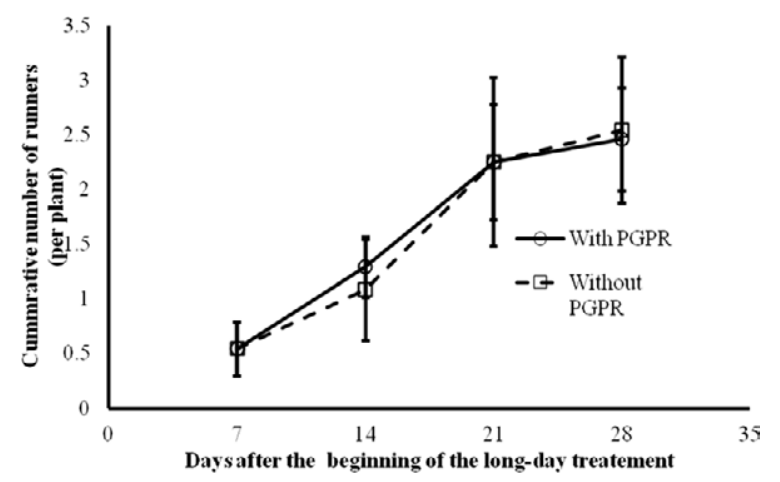

Fig. 1 Effects of PGPR application on the runner formation of $F$. vesca. Cumulative number of runners produced after the beginning of the long-day treatment was counted weekly. Bars indicates $\pm \operatorname{SD}(n=6)$. percentage of the single berries was not statistically different (Table 2).

Brix of the fruits was not statistically different (Table 3). Sugar content analysis by HPLC indicates sucrose is higher in the PGPR media, while glucose nor fructose were not statistically different between the two growth media (Table 3). Analyses of the sugar contents by sampling date show trends that sucrose and glucose were higher in the PGPR media most of the sampling date (data not shown).

Garden strawberry (F.× ananassa Duch.)

According to the experimental results on $F$. vesca, a similar set of experiments was conducted on octoploid garden strawberry $(F . \times$ ananassa Duch.) cultivar 'Tochiotome' and 'Hoko-wase'. Because the popular cultivation system in Japan employs low-temperature/SD treatment on the plantlets to induce flowers and flower-induced plants are planted in greenhouse/fields, experiments were conducted to elucidate the effect of the PGPR during flower induction treatment and after planting in pots. Runner plants were put on the first growth media on October 14, 2014, and repotted in 11 pots filled with the second growth media after the confirmation of the flower induction on December 16,2014 . The plants were kept in a greenhouse $\left(22 / 17^{\circ} \mathrm{C}\right.$ with natural illumination) at Utsunomiya University until April 30, 2015.

As anthesis day reflects the flower induction days and depth of dormancy of strawberries, effect of PGPR on flower induction was evaluated by counting the anthesis days. ANOVA indicates that PGPR affects anthesis day when it was supplied both during flower induction period and after the induction in 'Hoko-wase' but not in 'Tochiotome'. As a result, anthesis day was earlier in 'Hokowase' for which PGPR was supplied both during flower induction treatment and planted in pots, than those without PGPR throughout the experiment (Table 4). Days after anthesis to harvest were both not significantly different by the addition of PGPR (Table 4). Effects of PGPR on neither anthesis day, nor days after anthesis to harvest of the first fruit were not statistically significant for 'Tochiotome' (Table 4), but similar trend as 'Hoko-wase' was observed for anthesis day.

Total yield and number of fruits of the first fruit truss of 'Hoko-wase' was increased by application of PGPR during flower induction, so these factors were greater in those plants PGPR was supplied throughout the experiment compared to plants without PGPR during flower induction period (Table 5), whilst no statistical difference was observed in 'Tochi-otome', except for the fresh weight of the initial fruit. No statistical difference was observed in dry mass percentage for both cultivars either (Table 5).

Brix of the 'Hoko-wase' has a trend that it was negatively affected by the application of PGPR during flower induction even though there was no statistical difference at the level of $P<0.05$, while 'Tochi-otome' was not affected (Table 6). Unlike brix, sucrose, fructose, glucose content of 'Hoko-wase' was not statistically different by the application of PGPR in the growth media (Table 6). However, unlike 'Hoko-wase', sucrose content of 'Tochi-otome' was statistically $(P<0.05)$ lowered by the application of PGPR 
T. KUROKURA ET AL.

Table 1 Effects of PGPR application on growth parameters in F. vesca.

\begin{tabular}{cccccc}
\hline Growth media & $\begin{array}{c}\text { Days after the } \\
\text { beginning of the } \\
\text { long-day treatment }\end{array}$ & $\begin{array}{c}\text { Leaf area of the } \\
\text { newest unfolded } \\
\text { leaf }\left(\mathrm{mm}^{2}\right)\end{array}$ & $\begin{array}{c}\text { Cumulative number } \\
\text { of leaves emerged } \\
\text { (per plant) }\end{array}$ & $\begin{array}{c}\text { Petiole length of } \\
\text { the newest unfolded } \\
\text { leaf (mm) }\end{array}$ & $\begin{array}{c}\text { SPAD value of the } \\
\text { newest unfolded } \\
\text { leaf }\end{array}$ \\
\hline \multirow{2}{*}{ With PGPR } & 20 & - & $2.9 \pm 0.4$ & $78.3 \pm 17.8$ & $25.6 \pm 3.0$ \\
\multirow{2}{*}{ Without PGPR } & 34 & $2424.0 \pm 602.0$ & $4.4 \pm 0.7$ & $76.8 \pm 18.6$ & $26.2 \pm 2.6$ \\
& 20 & - & $2.6 \pm 0.7$ & $76.1 \pm 9.4$ & $24.9 \pm 1.5$ \\
& 34 & $1673.4 \pm 542.7$ & $4.3 \pm 0.7$ & $72.5 \pm 8.9$ & $26.5 \pm 1.8$ \\
\hline
\end{tabular}

Values are represented as mean $\pm \mathrm{SD}(n=6)$.

* significant at $P<0.05$. NS. not significant. ANOVA comparison was made between the treatments of the same sampling date.

Table 2 Effects of PGPR application on yield parameters in F. vesca.

\begin{tabular}{ccccc}
\hline Growth media & $\begin{array}{c}\text { Yield of the first fruit } \\
\text { truss (g/plant) }\end{array}$ & $\begin{array}{c}\text { FW of the initial } \\
\text { fruit }(\mathrm{g})\end{array}$ & $\begin{array}{c}\text { Number of fruits } \\
\text { in the first fruit truss }\end{array}$ & $\begin{array}{c}\text { Dry mass percentage } \\
(\mathrm{DW} / \mathrm{FW})\end{array}$ \\
\hline With PGPR & $4.14 \pm 2.00$ & $0.72 \pm 0.21$ & $6.83 \pm 2.23$ & $17.06 \pm 1.24$ \\
Without PGPR & $2.11 \pm 1.10$ & $0.52 \pm 0.19$ & $4.16 \pm 1.72$ & $17.38 \pm 0.97$ \\
\hline & $*$ & $*$ & $*$ & $\mathrm{NS}$ \\
\hline
\end{tabular}

Values are represented as mean $\pm \mathrm{SD}(n=6)$.

* significant at $P<0.05$. NS. not significant.

Table 3 Effects of PGPR application on sugar contents in F. vesca.

\begin{tabular}{|c|c|c|c|c|}
\hline & $\operatorname{Brix}(\%)$ & $\begin{array}{c}\text { Sucrose } \\
\left(\mathrm{mg} 100 \mathrm{mg}^{-1}\right)\end{array}$ & $\begin{array}{c}\text { Glucose } \\
\left(\mathrm{mg} 100 \mathrm{mg}^{-1}\right)\end{array}$ & 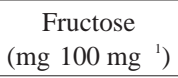 \\
\hline With PGPR & $6.2 \pm 2.1$ & $1.15 \pm 0.27$ & $2.24 \pm 0.69$ & $2.06 \pm 0.64$ \\
\hline \multirow{2}{*}{ Without PGPR } & $6.2 \pm 0.7$ & $0.78 \pm 0.44$ & $2.01 \pm 0.59$ & $2.08 \pm 0.51$ \\
\hline & NS & $*$ & NS & NS \\
\hline
\end{tabular}

* significant at $P<0.05$. NS. not significant.

Table 4 Effects of PGPR application during or after flower induction on flowering and harvest day in Fragaria $\times$ ananassa.

\begin{tabular}{|c|c|c|c|c|c|}
\hline \multirow{2}{*}{$\begin{array}{l}\text { Growth media during } \\
\text { flower induction (T1) }\end{array}$} & \multirow{2}{*}{$\begin{array}{l}\text { Growth media after } \\
\text { flower induction (T2) }\end{array}$} & \multicolumn{2}{|c|}{ Days from repotting to anthesis } & \multicolumn{2}{|c|}{ Days after anthesis to harvest } \\
\hline & & 'Hoko-wase' & 'Tochi-otome' & 'Hoko-wase' & 'Tochi-otome' \\
\hline \multirow{2}{*}{ Without PGPR } & Without PGPR & $105.57 \pm 14.20 \mathrm{a}$ & $75.67 \pm 8.04$ & $31.57 \pm 5.68$ & $32.53 \pm 2.91$ \\
\hline & With PGPR & $86.00 \pm 21.00 \mathrm{ab}$ & $75.44 \pm 14.30$ & $36.50 \pm 1.64$ & $33.94 \pm 3.15$ \\
\hline \multirow{2}{*}{ With PGPR } & Without PGPR & $82.00 \pm 12.80 \mathrm{ab}$ & $74.91 \pm 10.25$ & $32.67 \pm 2.25$ & $33.73 \pm 1.62$ \\
\hline & With PGPR & $69.22 \pm 12.31 \mathrm{~b}$ & $68.36 \pm 16.27$ & $33.11 \pm 4.86$ & $34.63 \pm 4.97$ \\
\hline $\mathrm{T} 1$ & & $* * *$ & NS & NS & NS \\
\hline $\mathrm{T} 2$ & & * & NS & NS & NS \\
\hline $\mathrm{T} 1 \times \mathrm{T} 2$ & & NS & NS & NS & NS \\
\hline
\end{tabular}

Values are represented as mean \pm SD $\left(n=8^{-14}\right)$. Values in each column followed by different letters are significantly different based on Tukey-Kramer test at $P<0.05$.

* significant at $P<0.05$, *** significant at $P<0.001$. NS. not significant.

during flower induction treatment (Table 6).

\section{DISCUSSION}

How PGPR interact with crops depends on the type of bacterial strain, plant species and their combination (Bhattacharyya and Jha, 2012). Some bacterial strains such as Agrobacterium spp. produce IAA so that the bacteria can alter the root morphology and results in the alteration of crop production in lettuce (Barazani and Friedman, 1999), while Bacillus spp. has been reported to secrete GA into soils when grown with alder (Gutiérrez-Mañero et al., 2001). Other functions of PGPR are such as solubilization of phosphate, nitrogen fixation, and pathogen defense. It has been reported that production of organic acids by PGPR contributes the conversion of insoluble form of $\mathrm{P}$ to soluble $\left(\mathrm{H}_{2} \mathrm{PO}_{4}^{-}, \mathrm{HPO}_{4}^{2-}\right)$ forms (Sundara et al., 2002; Richardson et al., 2009). PGPRs which enhance P solubilization have been isolated and their functions were studied in range of crops such as wheat, tomato and radish (Kim et al., 1998; Antoun et al., 1998; Singh and Kapoor, 1999; Kumar and Narula, 1999). In the case of other crops such as sugar cane, increase in brix has been reported as an indirect function of PGPR to control pathogen attack (Senthil et al., 2003).

Effects of Bacillus spp. as crop production improvement agents have been studied in many crops. For example, application of B. cereus on seeds of tomato has been reported that the treatment is effective to induce systemic resistance of the plant against several fungal diseases (Silva et al., 2004). This effect was explained as induction of systemic resistance against pathogens by inoculation of 

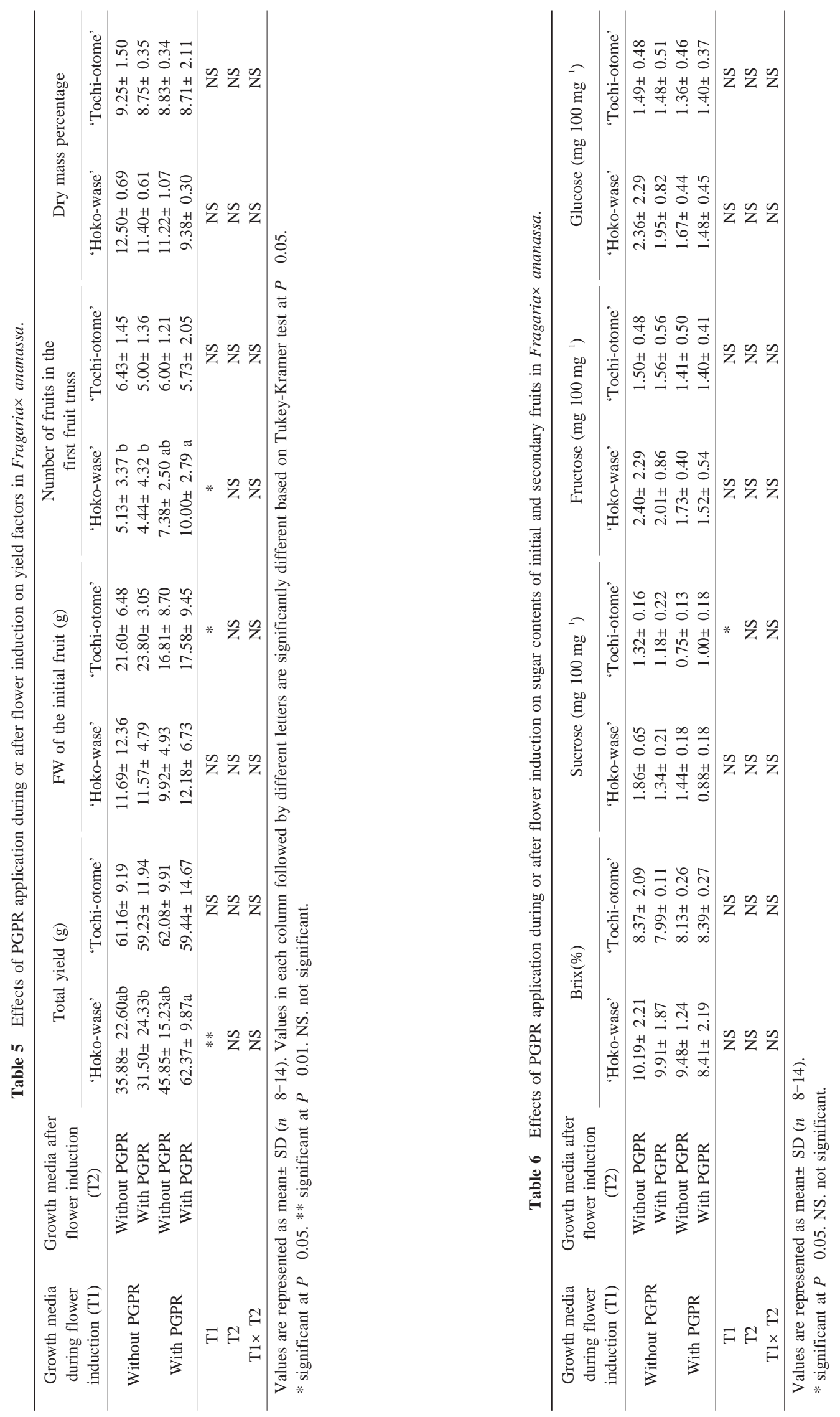
bacteria. Such effect has been reported in strawberry as well (Vestberg et al., 2004). Soil condition in this study was relatively 'clean', since the experiments were carried out in a greenhouse conditions and growth chambers. In addition, the basic matrix was commercial peat moss, and other than B. cereus containing 'biofertilizer' was not applied. No serious symptoms of any pathogen attack were observed during the experimental period either with or without PGPR (data not shown). These indicate the effect of $B$. cereus observed in this study is unlikely because of improvement of defenses systems against pathogens, as suggested in many other reports from field trials (Senthil et al., 2003; Silva et al., 2004; Tahmatsidou et al., 2006). What is different from other studies to this study, is that no additional fertilizers were applied over the experimental conditions. This means, the experiment in this study was conducted in relatively less-fertilized conditions. Therefore, effects of B. cereus observed in this study can be explained not by induction of systemic resistance but by other mechanisms mentioned earlier. One possible explanation is that the solubilization and enhancement of uptake of nutrients in the soil matrix. Several Bacillus spp. have been reported for their ability to enhance the solubilization and uptake of K (B. edaphicus, Sheng and He, 2006; B. mucilaginosus, Basak and Biswas, 2009) and $\mathrm{P}$ (B. subtilis, Swain et al., 2012; B. megaterium, Kang et al., 2014). It seems the effects of such bacteria become evident in less fertilized or difficult to grow soil conditions (Karlidag et al., 2013; Lingua et al., 2013; Sen and Chandrasekhar, 2014). The nutrition condition of the soil in this study was relatively poor compared to commercial cultivation conditions, as no additional fertilizer was applied at all.

It has been reported that the application timing of PGPR affects yield (Vestberg et al., 2004; Palencia et al., 2015). This is in line with the results of this study that the application during flower induction treatment can affect yield and numbers of fruits in the first fruit truss in 'Hokowase' (Table 5). It has been reported that the depth of dormancy, or length of chilling exposure after the flower induction has a negative effect on the number of flowers (Tehranifar et al., 1998). The garden strawberry cultivars used in this study have different dormancy depth so that 'Hoko-wase' flowered later than 'Tochi-otome' when no PGPR was applied (Table 4). Thus the early anthesis days by the application of PGPR only in 'Hoko-wase' indicates that PGPR may affects the depth of dormancy especially in cultivars with relatively higher chilling requirement. It has been reported that Bacillus spp. can secrete biologically active gibberellin, such as $\mathrm{GA}_{3}$ (Gutiérrez-Mañero et al., 2001). Effect of $\mathrm{GA}_{3}$ in garden strawberry has been reported as increment in the leaf area and number of flowers, acceleration of flower emergence as a result of dormancy break (Paroussi et al., 2002). As shown in the increment in the leaf area of $F$. vesca (Table 1), it may possible that $\mathrm{GA}_{3}$ is secreted by B. cereus and this broke the dormancy of 'Hoko-wase'. On the other hand, in 'Tochi-otome', which is less dormant cultivar, the effect of $\mathrm{GA}_{3}$ is relatively small, as modern varieties including this cultivar has been bred to reduce the requirement of exogenous application of gibberellins to reduce labor costs.

Previous studies have reported that inoculation of AM has no effect on the yield on garden strawberry cultivars (Bull et al., 2005; Garland et al., 2011). Other reports, however, argue that 'total yield' was increased by AM inoculation in the growth media (Douds et al., 2008; Bona et al., 2015). Analyses of the yield factors in this study indicates that at least in diploid 'Hawaii-4' and octoploid 'Hoko-wase', yields of the first fruit truss were increased by the application of PGPR as a result of the increments in the number of the fruits (Tables 2 and 5). This could be because the leaf area was increased by the application of PGPR in this study, but not by the photosynthetic ability per unit area, as it was reflected in SPAD (Table 1). The result that dry mass percentages were not increased in all three varieties used in this study, means that the increment in the leaf area and number of fruits were balanced. No effect of PGPR was found in days after anthesis to harvest (Tables 3, 4 and 5), even though it has been reported that light intensity below saturating level, which may be reflected in the photosynthesis activity, correlates with brix (Nestby and Trandem, 2013). In fact, brix of 'Hoko-wase' showed a decreasing trend (Table 6), probably due to the increment in the number of fruits, without increment in size (Table 5). It has been reported in soilless growing system, the combined application of Bacillus spp. with AM in the growth media resulted in the down regulation of brix (total soluble solid), whilst up-regulation of SPAD was observed (Palencia et al., 2015). Therefore, PGPR may increase the total yield, but may not contribute to increase the brix, as it has been reported in several researches (Esitken et al., 2010; Palencia et al., 2015).

Unlike brix, sugar content was affected by the application of PGPR in different ways among varieties examined in this study. In the case of diploid 'Hawaii-4', sucrose content was up-regulated by PGPR while brix as well as glucose and fructose were not statistically different (Table 3 ). On the other hand, sucrose in 'Tochi-otome' was downregulated (Table 6). Sucrose has been reported for its correlation with fruit ripening (Jia et al., 2013). In addition, anthocyanin content can be altered by the application of PGPR (Lingua et al., 2013). Experiments conducted in this study used fruits picking criteria which employ naked eyes, thus there is a possibility that enhancement in pigmentation process in 'Tochi-otome' resulted in the earlier picking even though no statistical difference was observed in the time between anthesis to harvest. In the case of 'Hawaii-4', as the fruits are white, it could be possible that the increment in sucrose resulted in the enhancement of ripening, but colour change was not recognized.

\section{CONCLUSION}

The yield of the first fruit truss was increased by the application of PGPR, B. cereus KI-2, in cultivar dependent manner while keeping brix. In addition, effects of PGPR were application-timing dependent so that the application during the flower induction period was effective, but application after that was neutral. In all experiments, dry mass 
as well as brix was not affected, thus it was expected the effect was not because of the improvement in the photosynthesis. These results indicate the possibility of PGPR application to maintain yield while reducing chemical fertilizer.

\section{ACKNOWLEDGEMENTS}

This research was sponsored by Bitech Co., Ltd., Japan. The sponsor has provided the biofertilizer used in the experiments, but was not involved in the design, implementations of the experiments, nor in the manuscript preparation.

\section{REFERENCES}

Antoun, H., Beauchamp, C. J., Goussard, N., Chabot, R., Lalande, R. 1998. Potential of rhizobium and bradyrhizobium species as plant growth promoting rhizobacteria on non-legumes: Effect on radishes (Raphanus sativus L.). Plant Soil 204: 5767.

Babalola, O. O., Osir, E. O., Sanni, A. I., Odhiambo, G. D., Bulimo, W. D. 2003. Amplification of 1-aminocyclopropane-1-carboxylic (ACC) deaminase from plant growth promoting rhizobacteria in Striga-infested soil. African J. Biotechnol. 2: 157-160.

Barazani, O., Friedman, J. 1999. Is IAA the major root growth factor secreted from plant-growth-mediating bacteria? J. Chem. Ecol. 25: 2397-2406.

Basak, B. B., Biswas, D. R. 2009. Influence of potassium solubilizing microorganism (Bacillus mucilaginosus) and waste mica on potassium uptake dynamics by sudan grass (Sorghum vulgare Pers.) grown under two Alfisols. Plant Soil 317: 235-255.

Battey, N. H., Le Mière, P., Tehranifar, A., Cekic, C., Taylor, S., Shrives, S. J., Hadley, P., Greenland, A. J., Darby, J., Wilkinson, M. J. 1998. Genetic and environmental control of flowering in strawberry. In "Genetic and Environmental Manipulation of Horticultural Crops" (ed. by Cockshull, K. E., Gray, D., Seymour G. B., Thomas, B.), CABI Publishing, Wallingford, UK, p 111-131.

Bhattacharyya, P. N., Jha, D. K. 2012. Plant growth-promoting rhizobacteria (PGPR): emergence in agriculture. World $\mathrm{J}$. Microbiol. Biotechnol. 28: 1327-1350.

Bona, E., Lingua, G., Manassero, P., Cantamessa, S., Marsano, F., Todeschini, V., Copetta, A., D’Agostino, G., Massa, N., Avidano, L., Gamalero, E., Berta, G. 2015. AM fungi and PGP pseudomonads increase flowering, fruit production, and vitamin content in strawberry grown at low nitrogen and phosphorus levels. Mycorrhiza 25: 181-193.

Bull, C. T., Muramoto, J., Koike, S. T., Leap, J., Shennan, C., Goldman, P. 2005. Strawberry cultivars and mycorrhizal inoculants evaluated in California organic production fields. Crop Manage. 4. doi:10.1094/CM-2005-0527-02-RS

Cardoso, I. M., Kuyper, T. W. 2006. Mycorrhizas and tropical soil fertility. Agric. Ecosyst. Environ. 116: 72-84.

Cattelan, A. J., Hartel, P. G., Fuhrmann, J. J. 1999. Screening for plant growth-promoting rhizobacteria to promote early soybean growth. Soil Sci. Soc. Am. J. 63: 1670-1680.

Cordier, C., Lemoine, M. C., Lemanceau, P., Gianinazzi-Pearson, V., Gianinazzi, S. 2000. The beneficial rhizosphere: A necessary strategy for microplant production. Acta Hortic. 350: 259-268.

Douds, D. D., Nahagashi, G., Shenk, J. E., Demchak, K. 2008. Inoculation of strawberries with AM fungi produced on-farm increased yield. Biol. Agric. Hortic. 26: 209-219.

Erturk, Y., Ercisli, S., Cakmakci, R. 2012. Yield and growth response of strawberry to plant growth-promoting rhizobacteria inoculation. J. Plant Nutr. 35: 817-826.

Esitken, A., Yildiz, H. E., Ercisli, S., Figen Donmez, M., Turan, M., Gunes, A. 2010. Effects of plant growth promoting bacteria (PGPB) on yield, growth and nutrient contents of organically grown strawberry. Sci. Hortic. 124: 62-66.

FAO. 2013. FAOStat, http://www.fao.org/faostat/en/\#data/. (accessed on December 25, 2016).

Garland, B. C., Schroeder-Moreno, M. S., Fernandez, G. E., Creamer, N. G. 2011. Influence of summer cover crops and mycorrhizal fungi on strawberry production in the Southeastern United States. HortScience 46: 985-992.

Gutiérrez-Mañero, F. J., Ramos-Solano, B., Probanza, A., Mehouachi, J., Tadeo, F. R., Talon, M. 2001. The plantgrowth-promoting rhizobacteria Bacillus pumilus and Bacillus licheniformis produce high amounts of physiologically active gibberellins. Physiol. Plant. 111: 206-211.

Hirakawa, H., Shirasawa, K., Kosugi, S., Tashiro, K., Nakayama, S., Yamada, M., Kohara, M., Watanabe, A., Kishida, Y., Fujishiro, T., Tsuruoka, H., Minami, C., Sasamoto, S., Kato, M., Nanri, K., Komaki, A., Yanagi, T., Guoxin, Q., Maeda, F., Ishikawa, M., Kuhara, S., Sato, S., Tabata, S., Isobe, S. N. 2014. Dissection of the octoploid strawberry genome by deep sequencing of the genomes of Fragaria species. DNA Res. 21: 169-181.

Jia, H., Li, C., Chai, Y., Xing, Y., Shen, Y. 2013. Sucrose promotes strawberry fruit ripening by stimulation of abscisic acid biosynthesis. Pak. J. Bot. 45: 169-176.

Kang, S. M., Radhakrishnan, R., You, Y. H., Joo, G. J., Lee, I. J., Lee, K. E., Kim, J. H. 2014. Phosphate solubilizing Bacillus megaterium mj1212 regulates endogenous plant carbohydrates and amino acids contents to promote mustard plant growth. Indian J. Microbiol. 54: 427-433.

Karlidag, H., Yildirim, E., Turan, M., Pehluvan, M., Donmez, F. 2013. Plant growth-promoting rhizobacteria mitigate deleterious effects of salt stress on strawberry plants (Fragaria $\times$ ananassa). HortScience 48: 563-567.

Kim, K. Y., Jordan, D., McDonald, G. A. 1998. Effect of phosphate-solubilizing bacteria and vesicular-arbuscular mycorrhizae on tomato growth and soil microbial activity. Biol. Fertil. Soils 26: 79-87.

Kumar, V., Narula, N. 1999. Solubilization of inorganic phosphates and growth emergence of wheat as affected by Azotobacter chroococcum mutants. Biol. Fertil. Soils 28: 301305.

Kurokura, T., Inaba, Y., Neri, D., Sugiyama, N. 2005. A morphological study of the development of the second inflorescences in strawberry (Fragaria $\times$ ananassa Duch.). Ann. Appl. Biol. 146: 511-515.

Lingua, G., Bona, E., Manassero, P., Marsano, F., Todeschini, V., Cantamessa, S., Copetta, A., D’Agostino, G., Gamalero, E., Berta, G. 2013. Arbuscular mycorrhizal fungi and plant growth-promoting pseudomonads increases anthocyanin concentration in strawberry fruits (Fragaria $\times$ ananassa var. Selva) in conditions of reduced fertilization. Int. J. Mol. Sci. 14: $16207-16225$.

Lowe, A., Rafferty-Mcardle, S. M., Cassells, A. C. 2012. Effects of AMF-and PGPR-root inoculation and a foliar chitosan spray in single and combined treatments on powdery mildew disease in strawberry. Agric. Food Sci. 21: 28-38.

Nestby, R., Trandem, N. 2013. Supplemental LED growth light in remontant strawberry at high latitudes. J. Berry Res. 3: 217-226.

Palencia, P., Martínez, F., Pestana, M., Oliveira, J. A., Correia, P. 


\section{T. KUROKURA ET AL}

J. 2015. Effect of Bacillus velezensis and Glomus intraradices on fruit quality and growth parameters in strawberry soilless growing system. Hortic. J. 84: 122-130.

Paroussi, G., Voyiatzis, D. G., Paroussis, E., Drogoudi P. D. 2002. Growth, flowering and yield responses to $\mathrm{GA}_{3}$ of strawberry grown under different environmental conditions. Sci. Hortic. 96: 103-113.

Richardson, A. E., Barea, J. M., McNeil, A. M., Prigent-Combaret, C. 2009. Acquisition of phosphorus and nitrogen in the rhizosphere and plant growth promotion by microorganisms. Plant Soil 321: 305-339.

Sen, S., Chandrasekhar, C. N. 2014. Effect of PGPR on growth promotion of rice (Oryza sativa L.) under salt stress. Asian J. Plant Sci. Res. 4: 62-67.

Senthil, N., Raguchander, T., Viswanathan, R., Samiyappan, R. 2003. Talc formulated fluorescent pseudomonads for sugarcane red rot suppression and enhanced yield under field conditions. Sugar Tech. 5: 37-43.

Sheng, X. F., He, L. Y. 2006. Solubilization of potassiumbearing minerals by a wild-type strain of Bacillus edaphicus and its mutants and increased potassium uptake by wheat. Can. J. Microbiol. 52: 66-72.

Silva, H. S., Romeiro, R. S., Filho, R. C., Pereira, J. L., Mizubuti, E. S. G., Mounteer, A. 2004. Induction of systemic resistance by Bacillus cereus against tomato foliar diseases under field conditions. J. Phytopathol. 152: 371-375.

Singh, S., Kapoor, K. K. 1999. Inoculation with phosphatesolubilizing microorganisms and a vesicular-arbuscular mycorrhizal fungus improves dry matter yield and nutrient uptake by wheat grown in a sandy soil. Biol. Fertil. Soils 28: 139-144.

Sønsteby, A., Heide, O. M. 2007. Long-day control of flowering in everbearing strawberries. J. Hortic. Sci. Biotechnol. 82: 875-884.
Sundara, B., Natarajan, V., Hari, K. 2002. Influence of phosphorus solubilizing bacteria on the changes in soil available phosphorus and sugarcane and sugar yields. F. Crops Res. 77: 43-49.

Swain, M. R., Laxminarayana, K., Ray, R. C. 2012. Phosphorus solubilization by thermotolerant Bacillus subtilis isolated from cow dung microflora. Agric. Res. 1: 273-279.

Tahmatsidou, V., O'Sullivan, J., Cassells, A. C., Voyiatzis, D., Paroussi, G. 2006. Comparison of AMF and PGPR inoculants for the suppression of Verticillium wilt of strawberry (Fragaria $\times$ ananassa cv. Selva). Appl. Soil Ecol. 32: 316-324.

Tehranifar, A., Miere, P. L., Battey, N. H. 1998. The effects of lifting date, chilling duration and forcing temperature on vegetative growth and fruit production in the Junebearing strawberry cultivar Elsanta. J. Hortic. Sci. Biotechnol. 73: 453-460.

Tilman, D., Cassman, K. G., Matson, P. A., Naylor, R., Polasky, S 2002. Agricultural sustainability and intensive production practices. Nature 418: 671-677.

Tulipani, S., Mezzetti, B., Capocasa, F., Bompadre, S., Beekwilder, J., de Vos, C. H. R., Capanoglu, E., Bovy, A., Battino, M. 2008. Antioxidants, phenolic compounds, and nutritional quality of different strawberry genotypes. J. Agric. Food Chem. 56: 696-704.

Ueki, M., Suzaki, T., Takano, K. 1993. Effects of starting date of short-day and low night temperature treatment on flowering and fruiting of strawberry cv. Nyoho. (in Japanese text with English summary) Bull. Tochigi Agric. Exp. Stn. 40: 75-82.

Vestberg, M., Kukkonen, S., Saari, K., Parikka, P., Huttunen, J., Tainio, L., Devos, N., Weekers, F., Kevers, C., Thonart, P., Lemoine, M. C., Cordier, C., Alabouvette, C., Gianinazzi, S. 2004. Microbial inoculation for improving the growth and health of micropropagated strawberry. Appl. Soil Ecol. 27: 243-258. 